International Association for the Psychology of Language Learning (IAPLL)

Journal for the Psychology of Language Learning

ISSN: 2642-7001. http://www.iapll.com/journal

Volume 2, June 2020, pp. 180-181

\title{
Book Review: Teacher Wellbeing by Sarah Mercer and Tammy Gregersen
}

Amanda Yoshida, Kanda University of International Studies, Japan

This book could not have come at a better time. Who would have thought that teachers all over the world would be temporarily changing their teaching methods in order to reach their learners? Teachers have had to reach inside themselves as well as out to each other in order to make sudden strides in their knowledge about technology and alternative approaches. Teacher wellbeing has never been more crucial.

The book comprises eight chapters, each one centering on a different aspect of the self. The authors take the eudaimonic view of wellbeing, which refers to the fact that wellbeing is about finding meaning and connection. In addition, the book utilizes Holmes' (2005) framework to explore the notion that individuals are composed of four types of wellbeing, that of physical, emotional, mental, and spiritual. Each chapter begins with an explanation of the theme followed by several activities to help language teachers reflect on the topics and apply the concepts to their own wellbeing. The activities draw on insights from positive psychology as well as teacher emotion research in terms of the common challenges and stressors that language teachers face.

In the introduction to the purpose of the book, the authors focus on the 'self' and explain why it is important to focus on oneself and the various tangents within the self. In order to help the reader consider their current situation, the reader is invited to take part in some mindset activities. In the next chapter called 'Me and My Workplace', the authors examine the ways that institutions can support their teachers which would increase their job satisfaction and reduce burnout. Although managers may well gain insights from such a chapter, readers can use these activities to think deeply about how they can empower themselves to engage in such activities 
Journal for the Psychology of Language Learning, Volume 2, June 2020, pp. 180-181. ISSN: 2642-7001.

http://www.iapll.com/journal

alone, invite colleagues near and far to engage with them, or to consider future possibilities for their own career trajectories.

The chapters that follow focus on the reader's mind, motivation, relationships, emotions and physical wellbeing, and they follow the same pattern of activities that can be explored alone or collaboratively with colleagues. The final chapter, entitled 'Me and My Future' invites readers to consider how they can manage their own wellbeing in the long run. It is all too easy for teachers to fall into their same old patterns of overwork, time mismanagement, and career/life imbalance which can lead to burnout. Taking time to learn how to sustain wellbeing practices will not only benefit the reader but also their colleagues as people working closely together tend to be influenced by each other.

This book would work well as a base for reflective practice groups because of the short chapters, each focusing on one prong of the self, and because there are a plethora of activities to choose from, which are appropriate for exploring in pairs or small groups. Chapters can be read in any order, and even within the chapters, readers can focus on pertinent sections depending on their needs. Each chapter includes a list of recommended reading for anyone so inclined to read further. At a time when teachers are feeling disconnected from their institutions, so many teachers are connecting online to form communities and groups to help each other learn new technology and approaches. This book reminds them not to ignore their own wellbeing, and to use these newly-formed connections to perhaps explore the topics together.

\section{Full Publication Details}

Title: Teacher Wellbeing

Authors: Sarah Mercer and Tammy Gregersen

Date: 2020

Publisher: Oxford University Press

Number of pages: 136

\section{Reference}

Holmes, E. (2005). Teacher wellbeing: Looking after yourself and your career in the classroom. London, UK: Taylor \& Francis. 